\title{
Article \\ Pre-Treatment C-Reactive Protein Predicts Survival in Small Cell Lung Cancer Patients
}

\author{
Anne Marie Stensvold ${ }^{1}$, Ninna Aggerholm-Pedersen ${ }^{2}\left(\mathbb{D}\right.$, Anne Winther-Larsen ${ }^{3}(\mathbb{C}$ \\ and Birgitte Sandfeld-Paulsen $3,4, *$ (D) \\ 1 Faculty of Health, Aarhus University, 8000 Aarhus, Denmark; am@stensvold.dk \\ 2 Department of Clinical Oncology, Aarhus University Hospital, 8000 Aarhus, Denmark; \\ aggerholm@oncology.au.dk \\ 3 Department of Clinical Biochemistry, Aarhus University Hospital, 8000 Aarhus, Denmark; \\ anne.winther.larsen@aarhus.rm.dk \\ 4 Department of Clinical Biochemistry, Viborg Regional Hospital, 8800 Viborg, Denmark \\ * Correspondence: birgne@rm.dk; Tel.: +45-2380-8068
}

Citation: Stensvold, A.M.; Aggerholm-Pedersen, N.;

Winther-Larsen, A.; Sandfeld-Paulsen,

B. Pre-Treatment C-Reactive Protein Predicts Survival in Small Cell Lung Cancer Patients. Onco 2021, 1, 114-122. https://doi.org/10.3390/ onco1020010

Academic Editor: Fred Saad

Received: 12 October 2021

Accepted: 5 November 2021

Published: 8 November 2021

Publisher's Note: MDPI stays neutral with regard to jurisdictional claims in published maps and institutional affiliations.

Copyright: (c) 2021 by the authors. Licensee MDPI, Basel, Switzerland. This article is an open access article distributed under the terms and conditions of the Creative Commons Attribution (CC BY) license (https:/ / creativecommons.org/licenses/by/ $4.0 /)$.
Simple Summary: Elevation of the inflammatory biomarker, C-reactive protein (CRP), is related to infection, inflammation, and malignancy. The aim of this registry study was to investigate whether the level of pre-treatment CRP in patients with small cell lung cancer (SCLC) could predict overall survival. From a dataset of 923 patients, we confirmed that a high level of CRP was associated with inferior survival and that addition of the CRP level to the already existing prognostic markers in SCLC increased the prognostic value. CRP can therefore be considered a useful tool in the prognostication of SCLC patients and potentially improve survival.

Abstract: Improved prognostication of small cell lung cancer (SCLC) patients could strengthen the treatment strategy and, thereby, potentially improve the overall survival (OS) of these patients. Creactive protein (CRP) has been proposed as a prognostic indicator of inferior survival, although so far, only based on data from smaller studies. Data on SCLC patients diagnosed from January 2009 to June 2018 were extracted from the Danish Lung Cancer Registry and the clinical laboratory information system. CRP measurements were divided at the clinical cut-off value of $8 \mathrm{mg} / \mathrm{L}$ or $75 \mathrm{nmol} / \mathrm{L}$ ) and stratified into quartiles. Cox proportional hazards model assessed the prognostic value of the CRP level. C-statistics further evaluated the biomarker's prognostic value. In total, 923 patients were included. A pre-treatment CRP level above the clinical cut-off significantly correlated to inferior OS (adjusted hazard ratio (HR) $=1.25$ (95\% confidence interval (CI): 1.08-1.46). When divided into quartiles, a level-dependent correlation was observed with only the highest quartiles significantly associated with OS (3rd quartile: adjusted HR $=1.26$ (95\% CI: 1.03-1.55) 4th quartile: adjusted $\mathrm{HR}=1.44$ (95\% CI: 1.17-1.77)). Adding CRP level to already well-established prognostic factors improved the prognostication of SCLC patients. In conclusion, high pre-treatment CRP level is an independent prognostic factor in SCLC patients.

Keywords: CRP; small cell lung cancer; survival; prognosis; biomarker

\section{Introduction}

Lung cancer is the leading cause of cancer-related death worldwide, with 1.76 million deaths in 2018 [1]. Small cell lung cancer (SCLC) is the most aggressive type of lung cancer associated with a high mortality and accounts for $15 \%$ of patients with lung cancer. To improve the overall survival (OS) of this patient subgroup, an optimised stratification of patients' mortality risk is needed to prepare a more personalised treatment for each patient. Currently, stage and performance status (PS) are the two most validated prognostic factors to consider. However, patients' prognosis can vary considerably within the same 
stage of disease as well as PS. Thus, additional prognostic markers are wanted to optimize prediction of SCLC patients' prognosis.

Inflammation is known to be associated with cancer in general, as it is believed to be involved in both initiation [2] and progression [3] of tumour growth. Monitoring inflammation is done by measuring various inflammatory biomarkers, most commonly the $\mathrm{C}$-reactive protein (CRP). CRP is a non-specific acute-phase reactant synthesized in many different types of cells, primarily hepatocytes [4]. The production increases rapidly if the inflammation is caused by infection or other tissue injury, whereas chronic disease often leads to only a moderate increase [5]. The prognostic impact of CRP has been widely explored in several cancer types, including colorectal cancers [6,7], pancreatic cancer [8-10], and non-small cell lung cancer (NSCLC) [4,11-17], and data have overall indicated a negative prognostic impact of high CRP level. In patients with SCLC, the relation between CRP and survival has only been explored in a limited number of studies with restricted sample sizes, revealing results bordering on insignificant [18-23]. Furthermore, a thorough investigation of whether CRP actually adds value to the already existing factors used to determine SCLC patients' prognosis has not been possible due to the limited sample sizes in studies.

Thus, the aim of this study was to evaluate the association between the pre-treatment CRP level and OS in a large Danish register-based cohort of SCLC patients. Furthermore, we wanted to evaluate whether pre-treatment CRP adds value to the already existing prognostic markers in this patient group.

\section{Materials and Methods}

\subsection{Patients}

This cohort has previously been described [24]. To summarize, this study included lung cancer patients registered in the Danish Lung Cancer registry (DLCR) [25] from 1 January 2009 to 26 June 2018. All Danish lung cancer patients are included in the DLCR as participation is mandatory by law, and the inclusion of incident cases since 2003 is estimated to be above $95 \%$. Thus, the registry contains more than 55,000 cases of lung cancer. The following information was extracted from DLCR at the time of diagnosis: sex, age, Eastern Cooperative Oncology Group (ECOG) PS, TNM-stage, as well as smoking status. Information on tumour characteristics was provided from The Pathology Data Bank [26]. The clinical laboratory information system (LABKA) supplied data on pretreatment CRP levels [27]. Mortality data, including date of death, was retrieved from the Danish Civil Registration System [28]. Combining of data between the registries was possible owed to the CPR number. CPR is a ten-digit number assigned to every Danish citizen allowing linkage of data at an individual level.

\subsection{CRP Measurement}

Pre-treatment plasma CRP level and date of sampling was extracted on each patient from LABKA. A CRP measurement was considered relevant if there was 90 days or less between CRP analysis and lung cancer diagnosis. If several results were available, only the one closest to diagnosis was chosen. If no CRP measurement in the last 90 days before diagnosis was available, the patient was excluded from analysis.

All plasma CRP levels were measured by a turbidimetric method using a fully automatic biochemical analyser system as part of the routine laboratory assessment. In September 2009, there was a change of concentration units for CRP in Denmark, changing from $\mathrm{nmol} / \mathrm{L}$ to $\mathrm{mg} / \mathrm{L}$. This means that our measurements from 1 January 2009 to 14 September 2009 are in the unit nmol/L and after this date our measurements of CRP level are in $\mathrm{mg} / \mathrm{L}$. Thus, the clinical cut off, above which CRP was deemed elevated also changed from $>75 \mathrm{nmol} / \mathrm{L}$ to $>8 \mathrm{mg} / \mathrm{L}$ This categorization was used for further analyses.

\subsection{Ethics}

The Danish Patient Safety Authority (no. 31-1521-400) and the Danish Data Protection Agency (no. 1-16-02-909-17) approved this study. This study was registry-based and did 
therefore not include any human biological material. According to Danish legislation, this means that patient consent and notification of the regional committees were unnecessary. Thus, the participants were not contacted.

\subsection{Statistical Analysis}

Patient characteristics are presented as numbers with percentages or median values with 5\% and 95\% percentiles. As part of the descriptive statistics, comparison of characteristics between groups was calculated by either the Chi square test or the rank sum test (age). OS and follow-up time were calculated from the time of diagnosis until the death of any cause or to the last follow-up date (1 July 2020). Patients still alive on the last day of follow-up were censored. All patients had a follow-up time of at least two years. OS was the primary endpoint. Patients with an OS of no more than one day were excluded. Estimates of median OS were calculated by the Kaplan-Meier method and compared by the log-rank test. Crude and adjusted hazard ratios (HRs) were calculated by the Cox proportional hazards model. Adjusted HR was estimated in two different models: either with CRP categorized as below or above the clinical cut off or with CRP divided into quartiles. A directed acyclic graph (DAG) was analysed for selection of confounders identified in the literature (Figure S1) [29]. Confounders were categorized except for age (continuous). Smoking status was not included in the analysis due to a very low number of non-smokers. To estimate whether the inclusion of CRP level to the well-established prognostic markers added additional prognostic value, C-statistic using the Harrell-s concordance index and the Akaike's information criteria (AIC) was performed on models with and without CRP included. Values in the Harrell-s concordance index range between 0.5-1.0, and 1.0 was defined as the perfect fit. For AIC, only a difference of 2 or more (arbitrary values) was considered an actual difference, and the model with the minimum AIC had the most precise prediction of OS. Likelihood-ratio tests were used to evaluate whether the added value was significant. All $p$-values were two-sided, and a $p$-value $\leq 0.05$ was considered significant. All statistical analyses were performed with Stata software version 16.1 (Stata Corporation, College Station, TX, USA).

\section{Results}

\subsection{Patients}

A total of 9044 patients were identified via the DLCR. Yet, 7662 of these patients had NSCLC, 66 patients did not have primary lung cancer and four patients had only one day of follow up, why they all were excluded, leaving 1312 SCLC patients for evaluation. Of these 1312 patients, 389 patients had no CRP measurement available in LABKA, leading to a final number of 923 included patients (Figure 1). A similar distribution of age, stage, PS and smoking status was observed among the included and excluded patients (Table S1), while a few more males were observed among the excluded patients compared to the included patients.

\subsection{Patient Characteristics}

The median age of all patients was 70 years (5-95\% percentiles: $52-83$ ) and $50 \%$ were women (Supplementary Table S1). The majority of patients had stage IV disease (59\%) and was former or current smokers (89\%). The patients were evenly distributed in the different PS groups with most of the patients having a good PS of 0 or 1 (55\%). The median CRP level in all patients was $18 \mathrm{mg} / \mathrm{L}$ (5-95\% percentiles: 1-201)/221 nmol/L (5-95\% percentiles: 14-2148).

An elevated CRP level above the clinical cut-off was found in 617 (67\%) of all included patients (Table 1). The median CRP level in these patients was $40 \mathrm{mg} / \mathrm{L}$ (5-95\% percentiles: 9-254)/391 nmol/L (5-95\% percentiles: 88-2375). In the 306 patients with a normal CRP level, the median level was $3 \mathrm{mg} / \mathrm{L}$ (5-95\% percentiles: $1-7) / 23 \mathrm{nmol} / \mathrm{L}$ (5-95\% percentiles: 7-75). Among patients with elevated CRP, there were a higher frequency of men than in 
patients with normal CRP level, just as a higher age, higher tumour stage and a higher PS were also observed in this group.

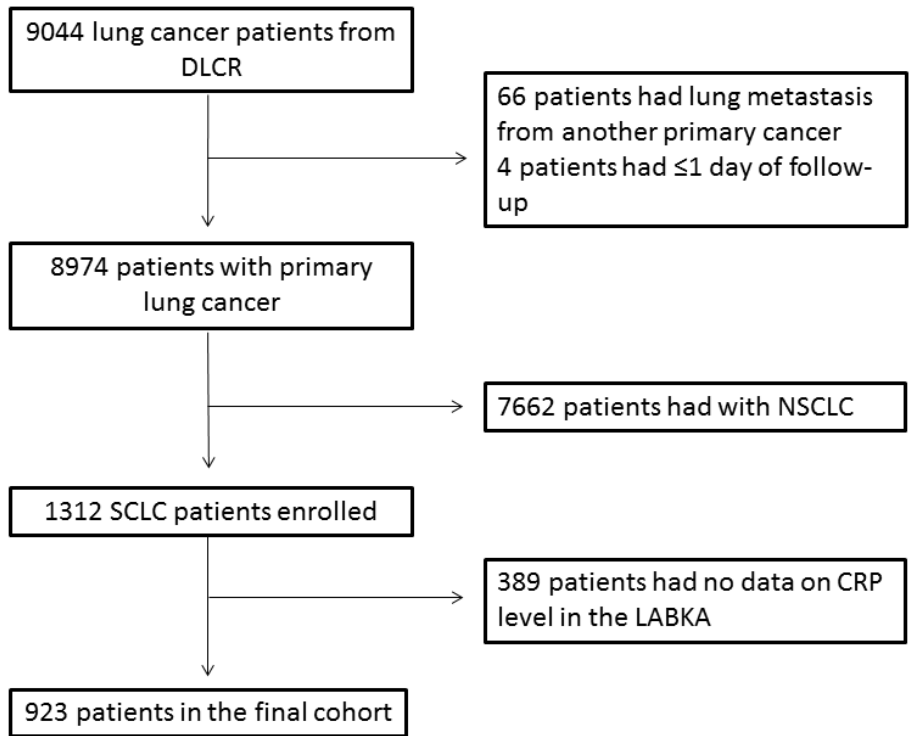

Figure 1. Flow chart of the inclusion and exclusion of patients. DLCR, Danish Lung Cancer Registry; LABKA, clinical laboratory information system; NSCLC, non-small cell lung cancer; SCLC, small cell lung cancer.

Table 1. Patient Characteristics at Time of Diagnosis $(n=923)$.

\begin{tabular}{|c|c|c|c|}
\hline & CRP Normal * & CRP Elevated * & $p$-Value ${ }^{\mathrm{a}}$ \\
\hline Total & $306(33 \%)$ & $617(67 \%)$ & \\
\hline $\begin{array}{l}\text { Age, median years }(95 \% \\
\text { percentiles })\end{array}$ & $68(52-82)$ & $70(53-84)$ & 0.033 \\
\hline \multicolumn{4}{|l|}{ Sex } \\
\hline Female & $177 \rightarrow(57 \%)$ & $288 \rightarrow(47 \%)$ & \multirow{2}{*}{0.002} \\
\hline Male & $129 \rightarrow(43 \%)$ & $329 \rightarrow(53 \%)$ & \\
\hline \multicolumn{4}{|l|}{ Stage } \\
\hline I & $26 \rightarrow(8 \%)$ & $21 \rightarrow(3 \%)$ & \multirow{5}{*}{0.001} \\
\hline II & $12 \rightarrow(4 \%)$ & $8 \rightarrow(1 \%)$ & \\
\hline III & $73 \rightarrow(24 \%)$ & $152 \rightarrow(25 \%)$ & \\
\hline IV & $173 \rightarrow(57 \%)$ & $375 \rightarrow(61 \%)$ & \\
\hline Unknown & $22 \rightarrow(7 \%)$ & $61 \rightarrow(10 \%)$ & \\
\hline \multicolumn{4}{|l|}{ Performance status, ECOG } \\
\hline 0 & $85 \rightarrow(28 \%)$ & $128 \rightarrow(21 \%)$ & \multirow{5}{*}{0.003} \\
\hline 1 & $103 \rightarrow(34 \%)$ & $188 \rightarrow(30 \%)$ & \\
\hline 2 & $46 \rightarrow(15 \%)$ & $103 \rightarrow(17 \%)$ & \\
\hline 3 & $39 \rightarrow(13 \%)$ & $132 \rightarrow(21 \%)$ & \\
\hline Unknown & $33 \rightarrow(11 \%)$ & $66 \rightarrow(11 \%)$ & \\
\hline \multicolumn{4}{|l|}{ Smoking } \\
\hline Never & $1 \rightarrow(0 \%)$ & $6 \rightarrow(1 \%)$ & \multirow{4}{*}{0.287} \\
\hline Former or current & $272 \rightarrow(89 \%)$ & $545 \rightarrow(88 \%)$ & \\
\hline Unknown & $33 \rightarrow(11 \%)$ & $66 \rightarrow(11 \%)$ & \\
\hline Median CRP (95\% percentiles) & $\begin{array}{l}3 \mathrm{mg} / \mathrm{L}(1-7) \text { or } \\
23 \mathrm{nmol} / \mathrm{L}(7-75)\end{array}$ & $\begin{array}{c}40 \mathrm{mg} / \mathrm{L}(9-254) \text { or } \\
391(88-2375) \mathrm{nmol} / \mathrm{L}\end{array}$ & \\
\hline
\end{tabular}

Abbreviations: CRP, c-reactive protein; ECOG, Eastern Cooperative Oncology Group. ${ }^{\text {a }}$ $p$-value was calculated by either the Chi square test or the rank sum (age). * the clinical cut off $(>8 \mathrm{mg} / \mathrm{L}$ or $>75 \mathrm{nmol} / \mathrm{L}$ ) was applied to define CRP as normal or elevated. The bold format indicates a new variabel with subcategories listed below. 


\subsection{Survival Outcome and Level of CRP}

The median OS for all patients was 7.1 months (95\% confidence interval (CI): 6.4-7.9). During follow-up, 866 patients (94\%) died. The median follow-up time for the $82(9 \%)$ patients still alive at last follow-up date was 5.4 months (95\% CI: $2.3-10.0$ ).

As illustrated in Figure 2a, an elevated CRP was significantly correlated with an inferior median OS (median OS: 5.86 months (95\% CI: 5.1-7.0) vs. 9.1 months (95\% CI: 8.4-10.4); $p<0.001)$. Furthermore, when dividing patients in quartiles based on their CPR level, a trend towards a level-dependent correlation to survival was observed with decreasing OS following increasing CRP levels (Figure 2b). In the univariate analysis, an elevated CRP level above $8 \mathrm{mg} / \mathrm{L} / 75 \mathrm{nmol} / \mathrm{L}$ together with stage III and IV disease, increasing age, male sex and high PS were found to significantly correlate with an inferior survival (Table 2). After adjusting for potential confounders, an elevated CRP level remained a significant predictor of inferior survival (adjusted HR $=1.25$ (95\% CI: 1.08-1.46)). However, when dividing the CRP levels into quartiles, this association was only observed in patients with CPR level in the 3rd and 4th quartiles. (3rd quartile: $18-59 \mathrm{mg} / \mathrm{L} / 221-560 \mathrm{nmol} / \mathrm{L}$ and 4th quartile: above $59 \mathrm{mg} / \mathrm{L} / 560 \mathrm{nmol} / \mathrm{L})$, resulting in an adjusted HR of 1.26 (95\% CI: 1.03-1.55) for the 3rd quartile and a HR of $1.44(95 \%$ CI: 1.17-1.77) for the 4th quartile.
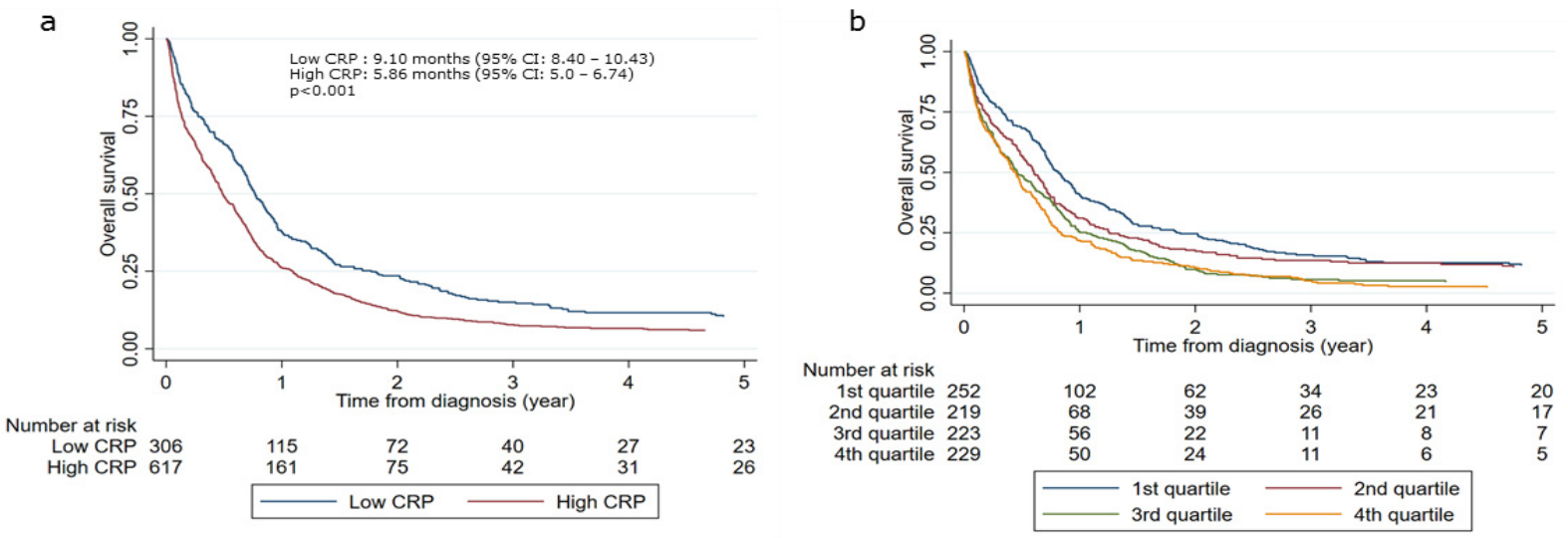

Figure 2. Kaplan-Meier curves of overall survival (OS) according to CRP level at time of diagnosis for patients with small cell lung cancer. (a) OS according to CRP level divided by the clinical cut-offs $>8 \mathrm{mg} / \mathrm{L}$ or $>75 \mathrm{nmol} / \mathrm{L}$. (b) OS according to CRP level divided by quartiles: 1 st quartile: $<5 \mathrm{mg} / \mathrm{L}$ or $<88 \mathrm{nmol} / \mathrm{L}$, 2 nd quartile: $5-18 \mathrm{mg} / \mathrm{L}$ or $88-221 \mathrm{nmol} / \mathrm{L}$, 3rd quartile: $18-59 \mathrm{mg} / \mathrm{L} / 221-560 \mathrm{nmol} / \mathrm{L}$, 4th quartile: $>59 \mathrm{mg} / \mathrm{L} />560 \mathrm{nmol} / \mathrm{L}$. Difference between groups were estimated by the log-rank test.

Table 2. Univariate and Multivariate Analysis of the Predictive Value of CRP for Overall Survival $(n=923)$.

\begin{tabular}{ccc}
\hline & $\begin{array}{c}\text { HR } \\
\mathbf{( 9 5 \%} \mathbf{C I})\end{array}$ & $\begin{array}{c}\text { Adjusted HR } \\
\mathbf{( 9 5 \%} \mathbf{~ C I})\end{array}$ \\
\hline CRP level & 1.00 & 1.00 \\
Normal & $1.42(1.23-1.64)$ & $1.25(1.08-1.46)$ \\
Elevated & 1.00 & 1.00 \\
CRP level & & \\
1st quartile & $1.22(1.01-1.48)$ & $1.06(0.86-1.31)$ \\
2nd quartile & $1.58(1.31-1.90)$ & $1.26(1.03-1.55)$ \\
3rd quartile & $1.75(1.45-2.11)$ & \\
4th quartile & & \\
Stage & 1.00 & \\
I & $1.16(0.57-2.34)$ & \\
II & $3.52(2.28-5.21)$ & \\
III & $7.15(4.69-10.58)$ & \\
IV &
\end{tabular}


Table 2. Cont.

\begin{tabular}{ccc}
\hline & $\begin{array}{c}\text { HR } \\
(\mathbf{9 5 \%} \mathbf{C I})\end{array}$ & $\begin{array}{c}\text { Adjusted HR } \\
\mathbf{( 9 5 \%} \mathbf{~ C I})\end{array}$ \\
\hline $\begin{array}{c}\text { Age, continuous variable } \\
\text { Sex } \\
\text { Female } \\
\text { Male }\end{array}$ & $1.03(1.03-1.04)$ & \\
Performance status, ECOG & 1.00 & \\
0 & $1.17(1.02-1.34)$ & \\
2 & 1.00 \\
$3+4$ & $1.47(1.22-1.77)$ \\
\hline
\end{tabular}

Abbreviations: CI, confidence interval; CRP, c-reactive protein; ECOG, Eastern Cooperative Oncology Group; HR hazard ratio. ${ }^{a}$ : 1 st quartile: $<5 \mathrm{mg} / \mathrm{L}$ or $<88 \mathrm{nmol} / \mathrm{L}$, 2nd quartile: 5-18 $\mathrm{mg} / \mathrm{L}$ or $88-221 \mathrm{nmol} / \mathrm{L}$, 3rd quartile: 18-59 mg/L/221-560 nmol/L, 4th quartile: $>59 \mathrm{mg} / \mathrm{L} />560 \mathrm{nmol} / \mathrm{L} .{ }^{\mathrm{b}}$ Adjusted HR was estimated in two different models with either CRP categorized as normal or elevated or CRP divided in quartiles. The bold format indicates a new variabel with subcategories listed below.

As a further evaluation of the impact of CRP, AIC and C-index were performed to establish whether inclusion of the CRP level added prognostic value to a model consisting of already recognized prognostic factors (Table 3). Here, an improvement of the model was seen after inclusion of the CRP level; though, only when the CRP level were evaluated by quartiles $(p=0.002)$.

Table 3. Prognostic Value Evaluation of Addition of CRP in quartiles to Established Prognostic Model.

\begin{tabular}{ccc}
\hline Model & AIC & C-Index \\
\hline (1) Stage + age + sex + PS & 8219 & 0.7322 \\
(2) CRP + stage + age + sex + PS & 8210 & 0.7355 \\
\hline
\end{tabular}

Abbreviations: AIC, Akaike's information criteria; CRP, c-reactive protein; PS, performance status.

\section{Discussion}

In this register-based study of 923 SCLC patients, we investigated the prognostic value of an elevated pre-treatment CRP level and found that a CRP level above the clinical cut-off value was correlated with an inferior survival, independent of other well-known factors such as stage and PS. Yet, when exploring the different levels of CRP, we found that the association was only significant for the two highest quartiles. Interestingly, we observed that adding CRP level divided in quartiles to the well-known prognostic factors actually increased the prognostication of survival in this patient group.

The association between an elevated level of CRP and poor survival has been demonstrated previously in several types of cancer [4,6-17]. Though, in SCLC patients, only a limited number of studies has explored this association [18-23]. As these studies are of small sample sizes ranging from 97 to 359 patients have used different CRP level cut-offs and shown results bordering on significance, it has not been possible to draw any firm conclusions based on them. Thus, a confirmation of these findings in a large validation cohort has been needed.

In this study, we present data on a SCLC cohort of 923 patients leaving it the largest sample size in the existing literature, which strengthens our results. Moreover, we explore the CRP level based on two stratifications: firstly, based on the clinical cut-off of $8 \mathrm{mg} / \mathrm{L} / 75 \mathrm{nmol} / \mathrm{L}$ that defines the normal range in Denmark and is applied in all Danish laboratories, and secondly in quartiles, which enables us to investigate a potential level-dependent correlation. In previous studies, the CRP cut-offs used were primarily low, between 5 and $10 \mathrm{mg} / \mathrm{L}[19,21,22]$, and thus close to the clinical cut-off value used in this study. Similar to the result of this study, these studies observed a significant association between elevated CRP and inferior survival, presenting adjusted HRs of 1.8 (95\% CI 1.13-2.88) [19], 2.13 (95\% CI 1.02-2.58) [22] and 2.75 (95\% CI 1.25-6.06) [21]. 
A higher cut-off value of $50 \mathrm{mg} / \mathrm{L}$ was used by Bernhardt et al. [18]. They included 350 patients with limited disease and presented a correlation between CRP level and overall survival in line with ours (adjusted HR $=1.43$ (95\% CI 1.00-2.04). None of the mentioned studies did further stratification of the CRP levels. Yet, Minami et al. [20] explored a leveldependent correlation between CRP and overall survival in 97 patients as they evaluated CRP level as a continuous variable and found a significant correlation (unadjusted HR 1.05 (95\% CI 1.01-1.09)). This result suggests that there also exists a significant association between lower levels of CRP and overall survival. Here, we validated the findings by Minami et al. by showing increasing HR with increasing CRP levels. However, for the lowest levels of CRP, we could not confirm a significant association when confounders were taken into account.

When discovering and developing new prognostic markers for use in the clinic, it is crucial to examine the value it actually adds to the already existing factors used for determining the prognosis. By employing c-statistics, we demonstrated the pre-treatment CRP level adds value in establishing the prognosis of the patient. Thus, our findings indicate that the CRP level could be a useful marker to incorporate in the general prognostication of patients in order to define a subset of patients with inferior prognosis requiring a more intensive treatment.

In addition, we found that a high CRP level was significantly linked to a more advanced stage of cancer and a worse PS. Among the previous literature on SCLC patients, only Hong et al. [19] and Shao et al. [22] analysed the association between CRP level and stage with similar findings. The found association between CRP level and cancer stage can be explained by the current understanding of chronic inflammation and cancer development. As suggested by Coussens et al. [3], inflammation can enhance tumour progression in already established cancer. It is therefore plausible that a higher degree of inflammation, as indicated by a higher CRP, is often followed by a higher cancer stage due to this progression. Furthermore, systemic inflammation affects many bodily functions, such as cognition, joints and bowel function, all factors that can worsen the PS of a patient. Yet, even though PS and stage is also associated with overall survival of cancer patients, this does not diminish our result of CRP as a prognostic factor as we found the association independent of PS and stage.

A great strength of this study is its magnitude. As registration in the Danish registries is mandatory by law and as the Danish Lung Cancer Registry has a very high completeness [25], a representative patient group is ensured reflecting the Danish population independently of economic or social differences. This improves the possibility to generalise the results to other populations. Patients were selected from a well-defined geographical area, reducing the risk of selection bias. The excluded patients are very alike the included patients, further reducing any bias of selection. Another advantage of this study is our extensive analysis of the data, including selecting confounders with DAG-based method and analysing the prognostication of CRP with AIC and C-statistics, which firmly establishes the value of our findings. These advantages of the study do naturally not exclude the presence of limitations. Firstly, we only included one CRP measurement, excluding the possibility of observing an effect of any fluctuations in CRP level. Secondly, a very low number of non-smokers was found in the cohort, therefore we did not include smoking as a confounder. However, as a strong association between CRP and smoking is well known, we could not rule out that the number of patients with missing data on smoking could lead to a bias in our results. Hence, sensitivity analyses were performed by comparing groups and performing c-statistics. As only seven non-smokers were included in this article, non-smokers and patients with missing data on smoking were grouped and compared to smokers. We did not find any difference in these two groups when comparing the clinical characteristics age, sex, stage of disease and performance status, and more importantly the CRP level. Further, by performing c-statistics smoking did not ad prognostic value to a model including age, sex, stage of disease, performance status, and CRP level. Thirdly, we did not have data on the different treatment modalities 
and patients' comorbidity and could therefore not look for association between this and overall survival and thus assess the need to adjust for these potential confounders in the multivariate analysis.

\section{Conclusions}

In conclusion, our study showed an association between a high CRP level and inferior survival in patients with SCLC. The association was found to be level-dependent and only significant for the highest CRP levels. Furthermore, we presented an improved prognostic model for SCLC by adding high CRP level to the already well-established prognostic factors, establishing CRP as a relevant prognostic factor to consider in SCLC patients.

Supplementary Materials: The following are available online at https: / www.mdpi.com/article / 10.3390/onco1020010/s1, Figure S1: Visualization of the directed acyclic graph (DAG) identifying confounders of CRPs effect on overall survival, Table S1: Patient Characteristics of included and excluded patients.

Author Contributions: Conceptualization, N.A.-P., A.W.-L. and B.S.-P.; methodology, N.A.-P., A.W.-L. and B.S.-P.; validation, N.A.-P., A.W.-L. and B.S.-P.; formal analysis, N.A.-P.; investigation, N.A.-P., A.W.-L. and B.S.-P.; resources, A.W.-L. and B.S.-P.; data curation, N.A.-P.; writing-original draft preparation, A.M.S.; writing-review and editing, A.M.S., N.A.-P., A.W.-L. and B.S.-P.; visualization, N.A.-P. and B.S.-P.; supervision, B.S.-P.; project administration, B.S.-P.; funding acquisition, B.S.-P. All authors have read and agreed to the published version of the manuscript.

Funding: This research was funded by the Dagmar Marshall Fund (grant number: 500020, 2019); and the Einar Willumsens mindelegat (grant number: 500028, 2019).

Institutional Review Board Statement: The study was conducted according to the guidelines of the Declaration of Helsinki, and approved by the Danish Patient Safety Authority (no. 31-1521-400) and the Danish Data Protection Agency (no. 1-16-02-909-17). This study was registry-based and did therefore not include any human biological material. Therefore, according to Danish legislation, ethical review and approval were waived for this study.

Informed Consent Statement: Patient consent was waived as patient consent are not required in register-based studies according to Danish legislation.

Data Availability Statement: In this study publicly archived datasets were achieved from the Danish Lung Cancer registry (DLCR) www.lungecancer.dk (accessed on 1 July 2020), The Pathology Data Bank www.patobank.dk (accessed on the 1 July 2020), the clinical laboratory information system (LABKA) www.auh.dk/om-auh/afdelinger/blodprover-og-biokemi (accessed on 1 July 2020) and the Danish Civil Registration System www.sundhedsdatastyrelsen.dk (accessed on 1 July 2020).

Conflicts of Interest: The authors declare no conflict of interest.

\section{References}

1. Bray, F.; Ferlay, J.; Soerjomataram, I.; Siegel, R.L.; Torre, L.A.; Jemal, A. Global cancer statistics 2018: GLOBOCAN estimates of incidence and mortality worldwide for 36 cancers in 185 countries. CA Cancer J. Clin. 2018, 68, 394-424. [CrossRef]

2. Aggarwal, B.B.; Shishodia, S.; Sandur, S.K.; Pandey, M.K.; Sethi, G. Inflammation and cancer: How hot is the link? Biochem. Pharmacol. 2006, 72, 1605-1621. [CrossRef]

3. Coussens, L.M.; Werb, Z. Inflammation and cancer. Nature 2002, 420, 860-867. [CrossRef]

4. Jing, X.; Huang, C.; Zhou, H.; Li, C.; Fan, L.; Chen, J.; Zhang, G.; Liu, Y.; Cui, Z.; Qi, D.; et al. Association between serum $\mathrm{C}$-reactive protein value and prognosis of patients with non-small cell lung cancer: A meta-analysis. Int. J. Clin. Exp. Med. 2015, 8, 10633-10639. [PubMed]

5. Sproston, N.R.; Ashworth, J.J. Role of C-Reactive Protein at Sites of Inflammation and Infection. Front. Immunol. 2018, 9, 754. [CrossRef] [PubMed]

6. Yamamoto, M.; Saito, H.; Hara, K.; Sugezawa, K.; Uejima, C.; Tanio, A.; Tada, Y.; Kihara, K.; Sakamoto, T.; Honjo, S.; et al. Combination of C-reactive protein and monocyte count is a useful prognostic indicator for patients with colorectal cancer. Vivo 2019, 34, 299-305. [CrossRef]

7. Woo, H.D.; Kim, K.; Kim, J. Association between preoperative C-reactive protein level and colorectal cancer survival: A meta-analysis. Cancer Causes Control 2015, 26, 1661-1670. [CrossRef] 
8. Szkandera, J.; Stotz, M.; Absenger, G.; Stojakovic, T.; Samonigg, H.; Kornprat, P.; Schaberl-Moser, R.; Alzoughbi, W.; Lackner, C.; Ress, A.L.; et al. Validation of C-reactive protein levels as a prognostic indicator for survival in a large cohort of pancreatic cancer patients. Br. J. Cancer 2014, 110, 183-188. [CrossRef] [PubMed]

9. Nurmi, A.M.; Mustonen, H.K.; Stenman, U.-H.; Seppänen, H.E.; Haglund, C.H. Combining CRP and CA19-9 in a novel prognostic score in pancreatic ductal adenocarcinoma. Sci. Rep. 2021, 11, 1-11. [CrossRef]

10. Mitsunaga, S.; Ikeda, M.; Shimizu, S.; Ohno, I.; Takahashi, H.; Okuyama, H.; Ueno, H.; Morizane, C.; Kondo, S.; Sakamoto, Y.; et al. C-Reactive Protein Level Is an Indicator of the Aggressiveness of Advanced Pancreatic Cancer. Pancreas 2016, 45, 110-116. [CrossRef]

11. Yu, X.; Zhao, J.; Shi, L.; Jin, Y.; Sun, Y.; Shi, X. Prognostic value of circulating C-reactive protein levels in patients with non-small cell lung cancer: A systematic review with meta-analysis. J. Cancer Res. Ther. 2014, 10, 160-166. [CrossRef] [PubMed]

12. Leuzzi, G.; Galeone, C.; Gisabella, M.; Duranti, L.; Taverna, F.; Suatoni, P.; Morelli, D.; Pastorino, U. Baseline C-Reactive Protein Level Predicts Survival of Early-Stage Lung Cancer: Evidence from a Systematic Review and Meta-Analysis. Tumori J. 2016, 102, 441-449. [CrossRef] [PubMed]

13. Liao, C.; Yu, Z.; Guo, W.; Liu, Q.; Wu, Y.; Li, Y.; Bai, L. Prognostic value of circulating inflammatory factors in non-small cell lung cancer: A systematic review and meta-analysis. Cancer Biomark. 2014, 14, 469-481. [CrossRef]

14. Zeng, Q.; Xue, N.; Dai, D.; Xing, S.; He, X.; Li, S.; Du, Y.; Huang, C.; Li, L.; Liu, W. A nomogram based on inflammatory factors c-reactive protein and fibrinogen to predict the prognostic value in patients with resected non-small cell lung cancer. J. Cancer 2017, 8, 744-753. [CrossRef]

15. Dirican, N.; Dirican, A.; Anar, C.; Atalay, S.; Ozturk, O.; Bircan, A.; Akkaya, A.; Cakir, M. A New inflammatory prognostic index, based on C-reactive protein, the neutrophil to lymphocyte ratio and serum albumin is useful for predicting prognosis in non-small cell lung cancer cases. Asian Pac. J. Cancer Prev. 2016, 17, 5101-5106. [CrossRef] [PubMed]

16. Baek, A.R.; Seo, H.J.; Lee, J.H.; Park, S.W.; Jang, A.S.; Paik, S.H.; Koh, E.S.; Shin, H.K.; Kim, D.J. Prognostic value of baseline carcinoembryonic antigen and cytokeratin 19 fragment levels in advanced non-small cell lung cancer. Cancer Biomark. 2018, 22, 55-62. [CrossRef]

17. Koch, A.; Fohlin, H.; Sörenson, S. Prognostic Significance of C-reactive protein and smoking in patients with advanced non-small cell lung cancer treated with first-line palliative chemotherapy. J. Thorac. Oncol. 2009, 4, 326-332. [CrossRef]

18. Bernhardt, D.; Aufderstrasse, S.; König, L.; Adeberg, S.; Bozorgmehr, F.; Christopoulos, P.; El Shafie, R.A.; Hörner-Rieber, J.; Kappes, J.; Thomas, M.; et al. Impact of inflammatory markers on survival in patients with limited disease small-cell lung cancer undergoing chemoradiotherapy. Cancer Manag. Res. 2018, 10, 6563-6569. [CrossRef]

19. Hong, S.; Kang, Y.A.; Cho, B.C.; Kim, D.J. Elevated Serum C-reactive protein as a prognostic marker in small cell lung cancer. Yonsei Med. J. 2012, 53, 111-117. [CrossRef]

20. Minami, S.; Ogata, Y.; Ihara, S.; Yamamoto, S.; Komuta, K. Pretreatment Glasgow prognostic score and prognostic nutritional index predict overall survival of patients with advanced small cell lung cancer. Lung Cancer Targets Ther. 2017, 8, 249-257. [CrossRef]

21. Park, M.-R.; Park, Y.-H.; Choi, J.-W.; Park, D.-I.; Chung, C.-U.; Moon, J.-Y.; Park, H.-S.; Jung, S.-S.; Kim, J.-O.; Kim, S.-Y.; et al. Progression-free survival: An important prognostic marker for long-term survival of small cell lung cancer. Tuberc. Respir. Dis. 2014, 76, 218-225. [CrossRef]

22. Shao, N.; Cai, Q. High pretreatment serum C-reactive protein level predicts a poor prognosis for combined small-cell lung cancer. Tumor Biol. 2015, 36, 8465-8470. [CrossRef]

23. Zhou, T.; Hong, S.; Wenhua, L.; Hou, X.; Huang, Y.; Zhao, H.; Liang, W.; Zhao, Y.; Fang, W.; Wu, X.; et al. A systemic inflammationbased prognostic scores (mGPS) predicts overall survival of patients with small-cell lung cancer. Tumor Biol. 2014, 36, 337-343. [CrossRef] [PubMed]

24. Sandfeld-Paulsen, B.; Aggerholm-Pedersen, N.; Winther-Larsen, A. Hyponatremia in lung cancer: Incidence and prognostic value in a Danish population-based cohort study. Lung Cancer 2021, 153, 42-48. [CrossRef]

25. Jakobsen, E.; Rasmussen, T.R. The Danish Lung Cancer Registry. Clin. Epidemiol. 2016, 8, 537-541. [CrossRef]

26. Patobank. 2021. Available online: https://www.patobank.dk/ (accessed on 1 July 2020).

27. Grann, A.F.; Erichsen, R.; Nielsen, A.G.; Frøslev, T.; Thomsen, R.W. Existing data sources for clinical epidemiology: The clinical laboratory information system (LABKA) research database at Aarhus University, Denmark. Clin. Epidemiol. 2011, 3, 133-138. [CrossRef] [PubMed]

28. Schmidt, M.; Pedersen, L.; Sørensen, H.T. The Danish civil registration system as a tool in epidemiology. Eur. J. Epidemiol. 2014, 29, 541-549. [CrossRef]

29. Greenland, S.; Pearl, J.; Robins, J.M. Causal diagrams for epidemiologic research. Epidemiology 1999, 10, 37-48. [CrossRef] [PubMed] 